The definitive version is available at www.blackwell-synergy.com

(http://onlinelibrary.wiley.com/doi/10.1111/1475-4754.00021/abstract)

DOI: $10.1111 / 1475-4754.00021$

(http://dx.doi.org/10.1111/1475-4754.00021)

CHEMICAL AND MINERALOGICAL ALTERATION OF CERAMICS

FROM A LATE BRONZE AGE KILN AT KOMMOS, CRETE: THE EFFECT ON THE FORMATION OF A REFERENCE GROUP

J. Buxeda i Garrigós ${ }^{1}$, V. Kilikoglou ${ }^{2}$, P.M. Day ${ }^{3}$ 


\title{
CHEMICAL AND MINERALOGICAL ALTERATION OF CERAMICS \\ FROM A LATE BRONZE AGE KILN AT KOMMOS, CRETE: THE EFFECT ON THE FORMATION OF A REFERENCE GROUP
}

\author{
J. Buxeda i Garrigós ${ }^{1}$, V. Kilikoglou ${ }^{2}$, P.M. Day ${ }^{3}$
}

${ }^{1}$ ERAUB, Department of Prehistory, Ancient History and Archaeology, University of Barcelona, c/ de Baldiri i Reixac, s/n, 08028 Barcelona, Catalonia, Spain.

${ }^{2}$ Laboratory of Archaeometry, Institute of Materials Science, N.C.S.R. Demokritos, Aghia Paraskevi, 15310 Attiki, Greece.

${ }^{3}$ Department of Archaeology and Prehistory, University of Sheffield, Northgate House, West Street, Sheffield S1 4ET, U.K. 


\begin{abstract}
The formation of reference groups comprises an important procedure in chemical provenance studies of archaeological pottery. Material from ancient kilns is thought especially suitable for reference groups, as it comprises a definite unit of past production. Pottery from the Late Minoan IA kiln excavated at Kommos, Crete was analysed in order to produce a reference group in this important area of Minoan ceramic production. The samples were characterised by a combination of techniques providing information on the chemistry, mineralogy and microstructure of the ceramic body. Initially the study was unable to establish, in a straightforward manner, a chemical reference group. Different ceramic pastes and a range of selective alterations and contaminations, affected by variable firing temperatures and burial environment, were shown to be responsible for the compositional variability. Procedures are described to compensate for such alterations and the perturbations in the data they produce.
\end{abstract}

\title{
Keywords
}

MINOAN, BRONZE AGE, KOMMOS, CRETE, POTTERY KILN, PROVENANCE, REFERENCE GROUP, NEUTRON ACTIVATION ANALYSIS, XRAY FLUORESCENCE, X- RAY DIFFRACTION, PETROGRAPHIC ANALYSIS, SCANNING ELECTRON MICROSCOPY, CONTAMINATION, ALTERATION. 


\section{Introduction}

Chemical reference groups in ceramic analysis

The formation of reference groups comprises one of the most crucial steps in ceramic provenance studies by chemical analysis. Generally, these reference groups are made up of ceramic compositions thought to be representative of the pottery, and therefore the raw materials, of a certain production area. By definition, the intra-group compositional variability of a reference group should be lower than that at an intergroup level, when it is compared to those representing other production locations. This principle has been expressed in the provenance postulate, first introduced by Weigand $e t$ al. (1977). In addition, it has become clear that a single production site can be represented by more than one chemical reference group, according to variation in clay paste recipes over time (Fillières et al. 1983) or according to functionally different recipes within the same chronological phase (Day et al. 1999). Therefore the major issue in provenance studies by chemistry is the establishment of valuable reference groups which are both reliable and relevant.

There have been several approaches to the formation of reference groups, which vary according to the geographical location and chronological period of the material under study. A very common procedure, especially in studies of the Aegean Bronze Age, has been the analysis of pottery thought to be produced at a particular site, and therefore expected to be chemically homogeneous. In this instance, reference groups (initially called control groups) were formed from ceramic material whose specific, common origin was assumed by archaeological criteria, usually according to morphological and decorative traits. Where possible, such groups were complemented with pottery sherds coming from the vicinity of kilns. Upon analysis, the common 
practice was to refine those groups by the removal of possible outliers and to assume that the remaining individuals exhibit the chemical signature of the area (Jones 1986, 48-49).

A second approach gives a lower weight to a priori archaeological provenance (presumed origin) and a higher priority to mathematical aspects of definition and discrimination of groups in multidimensional space. In this way, groups of chemically similar samples are identified, and reference groups are formed through additional consideration of stylistic and technological attributes, i.e. the 'archaeological' similarity. Through this procedure it becomes apparent that the archaeological and chemical criteria work in a complementary fashion (Bishop et al. 1982; Harbottle 1982). In order to relate the resulting chemical groups to a geographical provenance, the 'criterion of abundance' is often applied, which assumes that the group with the highest number of members is of local origin to an investigated site (Harbottle 1982). Of course, in the identification of local groups, this approach is also assisted by the analysis of wasters or pottery associated to kilns (Fillières et al. 1983).

\section{Integrated approaches to ceramic grouping}

Since the early 1980 s it has been recognised widely that ceramic provenance studies might be better approached by a combination of analytical techniques, in an attempt to overcome the problems arising from the application of a single technique (Maggetti 1981, Maniatis et al. 1984). Many such problems were related to the establishment of reference groups and it was petrographic analysis, already used systematically in ceramic studies since the 1930s (Shepard 1936), that raised many of the questions regarding reference groups in the Aegean (Day and Haskell 1995) and more specifically in Crete. In analyses of Minoan ceramics some types of coarse and 
fine pottery, previously thought local to their find-spot, were found to have been produced elsewhere (e.g. Riley 1983; Whitelaw et al. 1997; Day and Wilson 1998). In some instances these findings challenged the archaeological opinion on which the reference groups were based. In the resultant integrated projects, petrographic analysis comprised the main technique used in a complementary fashion with chemistry, thus giving emphasis to the ceramic fabric, which was treated as a reflection of the geological provenance and paste technology of manufacture.

Such an approach, combining stylistic, petrological and technological features, has been used as the basis for reference groups, which were then analysed in order to create the chemical profile of the particular fabric. Some of these fabrics have been related to a specific location of production.

\section{Raw materials and kilns as reference material}

The above methods also considered the comparison of the chemical composition of archaeological ceramics with that of natural clays sampled from specific locations. However, several possible complications are usually taken into account if the analysis of natural materials is included. In the first instance, the clays sampled close to an archaeological site might not be those used in antiquity and secondly potters usually manipulate and combine their raw materials in some fashion. The levigation, mixing or tempering of raw materials by the potter may alter the chemical composition of the bulk material (Arnold 1992). Therefore the straightforward comparison of clays and ceramic products may be problematic (Kilikoglou et al. 1988, Neff et al. 1988).

Given that only petrological data can be linked directly to geological information, total confidence in the chemical approach to provenance might seem to be guaranteed only by reference groups derived from kiln materials and wasters. After all, 
these form the best available evidence of the composition of a ceramic product from a specific location. This was, of course, appreciated in previous studies, but in some areas excavated production sites are either rare or totally absent. The Bronze Age of the Aegean comprises just such an archaeological period with very few pottery kilns discovered in comparison to the plentiful evidence for ceramics. As overlaps between chemical reference groups have long formed a problem in this area (e.g. Catling et al. 1980), the discovery of Bronze Age kilns in the Aegean is of particular interest. The pottery associated with such structures can provide the opportunity for the definite characterisation of reference groups in an area where so much chemical provenance work has been carried out.

\section{The LMIA kiln assemblage from Kommos}

The kiln excavated at the harbour site of Kommos in South-central Crete, dated to the Late Minoan IA period (c. $17^{\text {th }}-16^{\text {th- }}$ century B.C.) (Shaw et al. 1997; 2001), provides one of these rare opportunities. Lying on the coast at the south-western edge of the Mesara Plain, the kiln site was built in the remains of an impressive colonnaded court and had a large dump of pottery at its eastern end with ca. 26000 sherds. The significance of the kiln is even greater when two other factors are taken into account. First, the Mesara was the location of a substantial amount of pottery production during antiquity, and second that one of the most difficult provenance problems in Crete has been the discrimination of production centres within Central Crete (Wilson and Day 1994; Day et al. 1999). This inability to discriminate pottery has its roots in the similar, repetitive Neogene deposits found throughout the central area of the island (Jones 1986) and in the initially unsuitable reference groups, sampled according to archaeological criteria which were not always reliable (Day et al. 1999). Therefore, the analysis of 
pottery material from definite production centres may be the only way to resolve this kind of problem in Central Crete. The discovery of a pottery kiln at Kommos and the analysis of its associated material becomes important in that respect (Shaw et al. 2001).

In this paper, we present the procedure followed to establish a reference group for the LMIA kiln at Kommos. Initial analyses by thin section petrography (PE) and by neutron activation analysis (NAA) produced a number of groups, which were unsuitable as a chemical reference group. It was found that different paste recipes and selective alterations, the latter according to the original firing temperature of the sherds and the conditions of burial, together prevented the straightforward establishment of a reference group by means of chemical analysis alone. Subsequently, the combination of a number of other techniques, including X-ray diffraction (XRD), X-ray fluorescence (XRF) and scanning electron microscopy (SEM), was used to further the understanding of the chemistry, mineralogy and microstructure of the assemblage, thus enabling the refinement of the chemical data and the establishment of a reference group.

\section{Materials and methods}

The integrated programme of analysis was designed and executed using PE, SEM, NAA, XRF and XRD. The study considered 57 individuals sampled to represent the range of shapes and macroscopic fabrics present in pottery excavated inside and around the kiln structure. Except for those sherds which are clearly wasters, in other words the flawed products of drastic over-firing, it was assumed that much of this kiln dump was representative of the normal production of the kiln. 
Petrographic study of all ceramic thin sections was carried out under a Leitz Laborlux 12 polarizing microscope at magnifications of $x 25$ to $x 400$. The microstructures of all samples were studied on fresh, carbon coated, fracture surfaces, by means of SEM using a Philips 515 coupled to an EDAX 9900 analyser. The degree of vitrification and firing temperatures were then assessed following the procedure described elsewhere (Maniatis and Tite 1981; Kilikoglou 1994).

A portion of sample weighing at least $1.5 \mathrm{~g}$ was cut, cleaned, powdered, homogenised and left overnight to dry at $120^{\circ} \mathrm{C}$. For the NAA, approximately $150 \mathrm{mg}$ from the powder was weighed and heat-sealed in polyethylene vials. The same procedure was followed for the reference materials used, an International Atomic Energy Agency SOIL-7 and an in-house Lefkandi Brick standard. Samples and standards were irradiated in batches of ten ( 8 samples and two standards) at the swimming pool reactor of NCSR 'Demokritos' at a thermal neutron flux of $3 \times 10^{13}$ n.cm' ${ }^{2} \cdot \mathrm{s}^{-1}$. Eight days after irradiation, the samples and standards were measured for Sm, Lu, $\mathrm{U}, \mathrm{Yb}, \mathrm{As}, \mathrm{Sb}, \mathrm{Ca}, \mathrm{Na}, \mathrm{La}$ and twenty days after irradiation for $\mathrm{Ce}, \mathrm{Th}, \mathrm{Cr}, \mathrm{Hf}, \mathrm{Cs}, \mathrm{Sc}$, $\mathrm{Rb}, \mathrm{Fe}, \mathrm{Ta}, \mathrm{Co}$ and $\mathrm{Eu}$.

XRD was also carried out for the 57 individuals included in the study, using the same powders prepared for analysis. Measurements were performed with a Siemens D500 diffractometer working with the $\mathrm{Cu} \mathrm{K} \alpha$ radiation $(\lambda=1.5418 \AA)$, and graphite monochromator in the diffracted beam, at $1.5 \mathrm{~kW}$. Spectra were taken from 4 to $70^{\circ} 2 \Theta$, at about $1.8^{\circ} 2 \Theta / \mathrm{min}\left(\right.$ step size $=0.03^{\circ} 2 \Theta$; time $=1 \mathrm{~s}$ ). Finally, individuals 14,16 and 22 were chosen for a thermodiffractometric experiment because after SEM and XRD analyses they were found to exhibit the characteristics of the lowest firing temperatures in the present study. The analyses were performed using the Siemens D-500 diffractometer equipped with a high temperature chamber and a Positional Sensitive 
Detector (PSD). Several spectra were taken at room temperature, 600, 700, 750, 800, $850,900,950,1000,1050$ and $1100{ }^{\circ} \mathrm{C}$ using the same experimental conditions as above. A heating rate of $100^{\circ} \mathrm{C} / \mathrm{h}$ was employed, and the peak temperature was kept for $1 \mathrm{~h}$ before the spectra were recorded.

Also 18 individuals were analysed by XRF, using the powder prepared for analysis, in a Phillips PW 2400 spectrometer with a Rh excitation source, for 9 major and minor elements. From each individual a powdered portion of $0.3 \mathrm{~g}$ was dried and then fused to a glassy pill in dilution $1 / 20$ with lithium tetraborate. The quantification of the concentrations was obtained using a calibration line performed with 40 International Geological Standards. The elements determined comprised $\mathrm{Fe}_{2} \mathrm{O}_{3}$ (as total Fe), $\mathrm{Al}_{2} \mathrm{O}_{3}, \mathrm{MnO}, \mathrm{P}_{2} \mathrm{O}_{5}, \mathrm{TiO}_{2}, \mathrm{MgO}, \mathrm{CaO}, \mathrm{K}_{2} \mathrm{O}$ and $\mathrm{SiO}_{2}$. The loss on ignition (LOI) was measured by firing $0.3 \mathrm{~g}$, of dried powder, at $950^{\circ} \mathrm{C}$ for $3 \mathrm{~h}$.

\section{Results}

Petrographic Analysis

In thin section, the ceramics from the kiln are compatible with fabrics previously encountered in the analysis of pottery from the Mesara Plain, which are linked in geological terms to the schist, gneiss and ophiolite series of the surrounding hills (Myer and Betancourt 1990; Wilson and Day 1994). In a first classification, based on petrographic data, the assemblage was divided into six fabric groups. Additionally, Fabrics 1 and 2 have two sub-groups, according to the optical activity of their groundmass, suggestive of a difference in firing temperature. The following summary 
presents the basic characteristics of the petrographic fabrics. Full petrographic descriptions are reported in Shaw et al. (2001).

Group 1: Fine-grained fabric.

a: Kommos 7, 8, 9, 10, 17, 18, 20, 23, 31, 36 (10 individuals with low optical activity).

b: Kommos 5, 11, 12, 13, 14, 16, 22, 24, 26, 33, 35, 41, 42, 53 (14 individuals with high optical activity).

This group represents a fine fabric with few non-plastic inclusions. The micromass is generally yellowish-orange and displays streaks of calcareous clay in a darker matrix, which is taken to indicate the mixing of clays in the preparation of the clay body. The coarse fraction $(>0.2 \mathrm{~mm})$ contains sandstone, calcimudstone, polycrystalline quartz, quartz-biotite schist and altered volcanic rocks and serpentine up to $1.7 \mathrm{~mm}$ with a mode of c. $0.4 \mathrm{~mm}$, while the fine fraction includes carbonates, quartz, biotite, plagioclase, muscovite mica, chlorite and clinozoisite. The micromass varies from being highly optically active to only slightly optically active, reflected in the way this fabric group is split into sub-groups. This great difference bears witness to the use both high and low firing temperatures in firing what comprised essentially the same clay body.

Group 2: Medium coarse fabric.

a: Kommos 2, 3, 4, 15, 21, 25, 28, 29, 30, 38, 40, 45, 52, 57 (14 individuals optically slightly active).

b: Kommos 43, 46, 47, 48, 49, 50, 51 (7 individuals optically inactive). 
The medium coarse fabric contains few to common inclusions. The micromass orange-brown to grey-brown and is similar to Group 1. The coarse fraction of the nonplastics (> $0.1 \mathrm{~mm}$, up to $3 \mathrm{~mm}$, with coarse mode of c. $1 \mathrm{~mm}$ ) comprises a variety of schists, phyllites, amphibolite, fine-grained volcanic rocks, as well as a range of siliceous and calcareous sedimentary rock fragments. The fine fraction includes quartz, biotite, calcite, white mica, amphibole, epidote and clinozoisite. Most examples of this fabric are optically slightly active (2a), suggesting a generally higher firing temperature than for individuals of Group 1. In addition, some individuals of Group 2 (defined as 2b) present a very high fired (overfired) version, as evidenced by the optically inactive micromass and non-plastic inclusions that have suffered alteration and bloating.

Group 3: Medium coarse fabric with secondary calcite

Kommos 19, 27, 32, 34, 37, 39 (6 individuals).

This medium coarse fabric contains few inclusions in a micromass which appears generally more calcareous than the one of Group 2, possibly due to the secondary precipitation of calcite. The matrix is optically slightly active to inactive, indicating a high firing temperature for these individuals. The coarse fraction $(>0.1$ $\mathrm{mm}$, up to $2.35 \mathrm{~mm}$ ) includes sandstone and a lesser proportion of schist, siltstone and polycrystalline quartz; displaying a slightly different variant from the main medium coarse fabric.

Group 4: Coarse fabric with sand inclusions.

Kommos 1, 6 (2 individuals). 
This fabric is a coarser version of Group 2, with similar non-plastic inclusions. However, these occur more frequently and the clay matrix displays less evidence for clay mixing than the medium and fine equivalents.

Group 5: Siltstone fabric.

Kommos 54 (1 individual).

This fabric class is characterised by the presence of large, elongated grains of fine-grained, dark brown siltstone rock fragments grading into mudstone, together with a range of generally elongate, low grade metamorphic rock fragments in a quartz-rich red-firing clay. The inclusions range up to $4.2 \mathrm{~mm}$ long axis dimension. The optical activity of the matrix suggests a relatively low firing temperature. This fabric is distinct in petrological terms from Groups 1-4.

Group 6: Coarse red fabric with schist.

Kommos 44, 55, 56 (3 individuals).

This fabric is characterised by the presence of a rich array of low to medium grade metamorphic rock fragments including quartz biotite schist and quartz biotite clinozoisite schist, with rare metamorphosed volcanic rock fragments. The clay is red firing, and appears non-calcareous. The non-plastics of this fabric link it in petrological terms to Groups $1-4$, but they are different in shape and the clay matrix appears not to be based on a marl. They are more frequent and coarse, ranging up to $5.5 \mathrm{~mm}$ long axis dimension.

From the above group summaries, it becomes evident that fabric Groups 1 to 4 are closely related in mineralogical terms and the relatively small differences among 
them are mainly due to the grain size of the inclusions. However, Groups 5 and 6 exhibit clearly different petrographic characteristics. KOM 54 (Group 5) comprises different non-plastics, while the individuals in Group 6 differ from Groups 1-4 in terms of coarseness, texture and the nature of the micromass, while clearly sharing the same, local origin. All but one of the Group 5 and 6 individuals comprise clay slabs and bats which may comprise the furniture of the kiln, rather than its products. Therefore it seems that a local chemical reference group should be established from the individuals of Group 1-4.

Neutron Activation Analysis

The chemical concentrations were determined by means of NAA on the same individuals previously analysed by thin section. For further statistical analysis, the chemical data were transformed into logratios (Aitchinson 1986) according to:

$$
\mathbf{x} \in \mathrm{S}^{\mathrm{d}} \rightarrow \mathbf{y}=\log \left(\frac{\mathbf{x}_{-\mathrm{D}}}{\mathrm{x}_{\mathrm{D}}}\right) \in \mathrm{R}^{\mathrm{d}}
$$

where $\mathbf{x}$ is the raw $\mathrm{D}$ dimension compositional vector, $\mathrm{S}$ the d-dimensional simplex (d=D-1), $\mathbf{y}$ the logratio compositional vector and $\mathbf{x}_{-\mathrm{D}}$ is the vector $\left(\mathrm{x}_{1}, \ldots, \mathrm{x}_{\mathrm{d}}\right)$. Then the first step for the statistical evaluation of the chemical data was the calculation of the variation matrix, which is presented in Table 1 (Aitchinson 1990; Buxeda 1999). In this calculation the concentrations of the elements $\mathrm{Sb}, \mathrm{Tb}$, Ta and As were excluded for their poor counting statistics and some missing values. The columns of the variation matrix contain the variances resulting from the logratio transformation of each element (in 
rows) with the element as a devisor shown on the top of the respective column. The sum of the variances in each column is denoted by $\tau_{. i}$, while the sum of all $\tau_{. i}$ 's divided by twice the number of elements, gives the total variation (vt), which is a measure of variability within the chemical data set. The total variation in this case was found to be 0.60 , which is relatively low and indicates a broadly monogenic origin for the analysed individuals (Buxeda and Kilikoglou in press), as would be expected with what comprises a production group. Another interesting feature in the variation matrix is the ratio $\mathrm{vt} / \tau_{\mathrm{i}}$, for each element, which is used as an estimate of the elements' contribution to the total variation. The lower this value is, the higher is those elements contribution to the total variation. It is clear from the variation matrix that several elements have an important contribution in the existing variability in the chemical data (i.e. $v t / \tau_{\text {. }}<0.3$, or $<30 \%): \mathrm{Rb}\left(\tau_{\mathrm{Rb}}=26.91 \%\right), \mathrm{Cs}\left(\tau_{. \mathrm{Cs}}=25.61 \%\right), \mathrm{Na}\left(\tau_{\mathrm{.Na}}=25.4 \%\right), \mathrm{Ca}\left(\tau_{\mathrm{Ca}}=22.5 \%\right) . \mathrm{On}$ the contrary, La contributes the least to the chemical variability $\left(\tau_{. \mathrm{La}}=90.85 \%\right)$ and therefore is considered to be the most stable element in the present data set. For this reason it was assumed that its distribution is the least affected by any possible perturbation, representing only natural variation. The concentration of this element was used as the divisor in the logratio transformation of the raw data, which were then used for statistical analysis. Therefore, all data are expressed as relative to La values in a logarithmic scale.

Cluster analysis was performed on the subcomposition $\mathrm{Sm}, \mathrm{Lu}, \mathrm{U}, \mathrm{Yb}, \mathrm{Ca}, \mathrm{Na}$, $\mathrm{Ce}, \mathrm{Cr}, \mathrm{Hf}, \mathrm{Cs}, \mathrm{Sc}, \mathrm{Rb}, \mathrm{Fe}, \mathrm{Eu}$ and La, as logratios over the concentration of La. The square mean euclidean distance was used as an inter-sample distance and the centroid clustering algorithm was employed on the distance matrix. The dendrogram (Figure 1) produced by the CLUSTAN program, appears to have a relatively complex structure, not expected for pottery coming from kiln material of a single production center. As 
can be seen in Figure 1, the majority of the individuals analysed (41 out of the 57) cluster together in Cluster A at the left side of the dendrogram, while the rest form some smaller, but distinct clusters. The main Cluster A contains, as expected, most of the individuals of petrographic Groups 1, 2, 3 and 4, while the other individuals from these petrographic groups are classed in Clusters B, D and E, which have been separated on the basis of $\mathrm{Na}, \mathrm{Cs}$ and $\mathrm{Rb}$ relative concentrations (Table 2). Cluster $\mathrm{B}$ is distinct from the rest, mainly due to an elevated relative $\mathrm{Na}$ content, while the Cluster's $\mathrm{Cs}$ and $\mathrm{Rb}$ present similar relative values to the main Cluster A. Cluster D exhibits an elevated Cs relative content and possibly also relatively elevated $\mathrm{Rb}$, with no differences in $\mathrm{Na}$, while Cluster E displays very low relative $\mathrm{Rb}, \mathrm{Cs}$ and $\mathrm{Na}$. On the other hand, Cluster $\mathrm{C}$ contains individuals with relatively low $\mathrm{Ca}$ and high $\mathrm{Na}$, and corresponds to the petrographic Groups 5 and 6, which comprise different clays. These non-calcareous clays (Ca content $<4-5 \%$ ) were mainly used for bats and not for the common utilitarian pottery found in the area of the kiln.

In summary, the effort to characterise the kiln pottery by chemical and petrographic analysis revealed some marked differences in mineralogy and chemistry for a very few individuals (Groups 5 and 6 / Cluster C). These were immediately understandable. However, the structure revealed in the chemical data (Clusters A, B, D and E) for the closely related Groups 1-4 was more problematic. It seems that grain size/texture is not responsible for the chemical variation. However, there was an indication, through the observation of the optical activity of the micromass and through the SEM analyses described below, of a connection between Clusters B, D and E and the firing temperature of their member individuals. This link was then investigated further with an array of techniques. 
Comparison with $X$-ray diffraction and scanning electron microscopy

The chemical results from NAA were then compared with the XRD/SEM data in order to reveal the cause of the above variations. To extract the maximum information, the XRD (firing experiments and as received state) and SEM data were examined in conjunction with the already discussed petrographic groups and the chemical compositions of the individuals. For this reason, one nominal variable with several categories was defined according to the presence or absence of crystalline phases by XRD (Heimann 1982, Maggetti 1982). More specifically, categories were defined according to the significant differences arising from the presence or absence of chlorite, the formation of pyroxene and the decomposition of illite-muscovite. These categories exhibit an increase in firing temperature, which is broadly consistent with the SEM evaluation of degree of vitrification. The broad equivalent firing temperatures can be estimated as:

- above $950-1000^{\circ} \mathrm{C}$ for category 'No I-M' (no illite-muscovite), because of total decomposition of illite-muscovite.

- below $950-1000^{\circ} \mathrm{C}$ but above $850^{\circ} \mathrm{C}$ for category ' $\mathrm{D}$ and I-M' (pyroxene along with illite-muscovite), because of pyroxene formation.

- Below $850^{\circ} \mathrm{C}$ but above $750^{\circ} \mathrm{C}$ for the category 'No Cl, No D' (no chlorite and lack of pyroxene), because of lack of chlorite.

- Below $750^{\circ} \mathrm{C}$ for the category 'Cl” (chlorite present). 
Given that the elements that exhibit the highest variation are $\mathrm{Cs}, \mathrm{Na}$ and $\mathrm{Rb}$, their logratios over La were examined in conjunction with the mineralogical (petrographic and mineralogical temperature scale) classification. In Figure 2, the vertical axis contains the logratio values of Cs over La, while the horizontal axis is divided according to the petrographic Groups 1, 2 and 3, and the firing temperature scale, which was described above. It should be noted that in this graph only the individuals belonging to petrographic Groups 1, 2 and 3 are considered, because they represent typical local fabrics, while Group 4 contained only 2 individuals. It can be seen that the majority of the relative values of Cs (Figure 2, shaded area) fall roughly between 1 and 1.7 which probably represents the typical concentration of this element. The limits in all plots were defined in such a way that the clear outliers in the dendrogram of figure 1 were excluded from the main range. On the contrary, those allocated to the Group 1 category 'Cl' (KOM16, 21, 22 and 26) exhibit values clearly higher. At the same time, some individuals allocated to Group 1 category 'D and I-M' exhibit values below 1.7 (KOM10, 18, 17 and 20). No significant deviations from the main range of values are found in any other category or group, with the possible exception of slightly low relative value for one individual in Group 2 category ' $\mathrm{D}$ and IM' (KOM40).

Similarly, the majority of the relative values of $\mathrm{Rb}$ fall within the range between 1.9 and 0.9 (Figure 3, shaded area). It can be seen that several individuals exhibit values considerably below the set limits. As was the case with the relative values of $\mathrm{Cs}$, those individuals are allocated to Group 1 (fine fabric) category 'D and I-M' (KOM18 and 10) and, to a lesser extent, in Group 2 (medium coarse fabric) category 'D and I-M' (KOM2). Moreover, individuals allocated to two other categories also present lower 
relative values of Rb: KOM49, from Group 2 category 'No I-M' and KOM37, which belongs to Group 3 category 'No I-M'.

The third plot of that kind contains the relative Na values plotted against the defined mineralogical groups and categories. It can be seen that a central range exists broadly between 5.9 and 5.35 (Figure 4, shaded area). From this range, several individuals exhibit either higher or lower values. All individuals that lie above the upper range, with the exception of KOM24 (Group 1 category 'D and I-M'), are allocated to the category 'No I-M', either of Group 2 (KOM43, 49, 50, 46, and 51) or Group 3 (KOM27 and 37). On the contrary, for the lower relative values the picture is broadly similar to that already observed for $\mathrm{Cs}$ and, to a lesser extent, for $\mathrm{Rb}$. The individuals which present low relative values are allocated again to Group 1 category 'D and I-M' (KOM5, 8, 10, 11, 17, 18, 20 and 35) as well as to Group 2 category 'D and I-M' (KOM57).

The above results clearly show a variable behaviour of the alkalis determined and it became evident that the $\mathrm{K}$ content should be determined in order to complete the picture. Therefore, a representative sample of eighteen individuals was analysed by XRF for major elements (Table 2). The sample covered all petrographic groups and ranges of relative concentrations of the categories that have been shown to present problems. It was not possible to analyse all the individuals by XRF due to sample availability. The relative logratio concentrations of $\mathrm{K}_{2} \mathrm{O}$ over La are also plotted against the mineralogical groups and temperature scales (Figure 5). It can be seen that there is a considerable number of individuals classed in Group 1 category 'D and I-M' that exhibit low $\mathrm{K}_{2} \mathrm{O}$ relative concentrations. Individuals KOM10, 17, 18 and 20 were also below the typical range in the plot for Na (Figure 4) and Cs (Figure 2), while KOM10 and 18 were low in $\mathrm{Rb}$ (Figure 3). The other interesting feature here is that all four high fired 
individuals analysed exhibit low $\mathrm{K}_{2} \mathrm{O}$ concentrations. The same individuals are also outliers in the case of $\mathrm{Na}$ (Figure 4), in this case due to their high values.

To summarise, the majority of the individuals analysed exhibit similar relative concentrations of $\mathrm{Na}, \mathrm{Rb}, \mathrm{Cs}$ and $\mathrm{K}$, but with some significant exceptions as follows:

1- Most of the individuals that belong to Group 2 category 'No I-M' and Group 3 category 'No I-M' (high fired) present high relative values of Na. At the same time, some of the individuals of the above groups exhibit low relative values of $\mathrm{Rb}$ and $\mathrm{K}$, while relative values of $\mathrm{Cs}$ for all individuals of Groups 2 and 3 lie in the central range.

2- Some individuals belonging to Group 1 category 'D and I-M' exhibit low relative values in, more or less, all four alkalis analysed. There are a few more instances where low relative values for the alkalis are observed, but in a nonsystematic fashion.

3- All individuals of Group 1 category 'Cl' (low fired) exhibit high relative values of Cs.

\section{Discussion}

From the presentation of the analytical data it becomes evident that there are three different cases of outliers in the analyses of the Kommos Kiln pottery. In the first case there are high fired individuals that exhibit high $\mathrm{Na}$ values, in the second case medium fired individuals exhibiting low values generally in the alkalis and, in the third one, low fired individuals that exhibit high Cs values. 


\section{High-fired individuals with high Na content.}

If we concentrate our attention on the first case, and examine the XRD spectra of all the individuals that belong to it (high value outliers in Figure 4), it can be seen that all of them, except KOM51, contain the mineral phase of analcime, which is a sodium zeolite. A representative XRD spectrum with the characteristic line for analcime is shown in Figure 6 and comes from individual KOM49. Zeolites are typical secondary mineral phases in ceramics, crystallizing during burial. The crystallization of zeolites as secondary phases has been reported as deriving from the decomposition of gehlenite (Maggetti 1981; Heimann and Maggetti 1981; Jornet 1982; Walter 1988). Their presence has been linked to a possible crystallization from free material left by the alteration of a glassy phase in overfired calcareous pottery (Buxeda 1999; Buxeda and Cau 1997). The latter was first proposed by Picon (1976) in order to explain similar chemical deviation in elemental concentrations and has also been suggested in other cases, but without the actual mineralogical determination of zeolites (Segebade and Lutz 1980; Lemoine et al. 1981; Schmitt 1989; Picon 1991). Analcime is therefore responsible for fixing sodium from the environment and results in the enrichment of this element in the pottery. This can be seen in the bivariate plot of analcime (semiquantified in counts per second of its $5.59 \AA$ peak $\left.-15.8^{\circ} 2 \theta\right)$ versus $\ln (\mathrm{Na} / \mathrm{La})$, which shows a clear direct correlation (Figure 7). The alteration of the glassy phase and fixation of Na may have also led to some leaching of $\mathrm{K}$ and, to a lesser extent, of $\mathrm{Rb}$. This becomes evident from individuals KOM46 and 49 (Group 2 category 'No I-M'), as well as individuals KOM27 and 37 (Group 3 category 'No I-M'). Moreover, individuals KOM37 and 49, which present the highest analcime values and at the same time exhibit the lowest relative $\mathrm{K}_{2} \mathrm{O}$ values, also exhibit some leaching of $\mathrm{Rb}$. This indicates an 
inverse correlation between the leaching of alkalis and the crystallization of analcime. Therefore, it is possible that for highly fired and overfired pottery (category 'No I-M') two processes have taken place producing the alteration of the glassy phase and a subsequent crystallization of analcime. From the first one, a leaching of some alkalis is produced, observed in values of $\mathrm{Rb}$ and $\mathrm{K}_{2} \mathrm{O}$, while $\mathrm{Cs}$ seems not to be involved, suggesting that the latter does not enter to any great extent into the composition of the glassy phase. This different behaviour of Cs can be explained by its larger atomic size in comparison with the rest of the alkalis determined. However the crystallization of analcime, combined with the subsequent enrichment of $\mathrm{Na}$ from the burial environment, does not allow us to observe whether the previous leaching of alkalis also affects Na. The behaviour of $\mathrm{Na}$ is independent of the rest of the alkalis and is reflected in the $\tau_{\mathrm{Na}-\mathrm{Rb}}$ value of 0.22 , the highest after the $\tau_{\mathrm{Na}-\mathrm{Ca}}$ value $(0.25)$. However, the latter is due to the existence of non-calcareous pottery in the sample analysed.

\section{Medium-fired individuals with low alkali values.}

In relation to the second type of variation, that of the leaching of the alkalis, the picture is very different from the case discussed above. Here, several individuals from Group 1 (fine fabric) category 'D and I-M', and a smaller number from Group 2 (medium coarse fabric) category ' $\mathrm{D}$ and I-M', present low relative values in $\mathrm{Cs}, \mathrm{Rb}$, $\mathrm{K}_{2} \mathrm{O}$ and $\mathrm{Na}$. This applies to a considerable number of individuals, as can be observed in Figures 2 to 5. The degree of leaching and the particular individuals affected may be variable but the trend is rather clear. These data indicate that the leaching of the alkalis seems to have taken place in at least some of the individuals allocated to those categories. Such a process, specifically the leaching of alkalis, has been observed in a another kiln site at Abella, Spain, which produced Hispanic Terra Sigillata (Buxeda 
1999). The mobility of alkalis is well documented in pottery studies (e.g. Sayre et al. 1971; Asaro et al. 1975; Olin et al. 1978), and it has also been detected through simulation experiments with either positive (Segebade and Lutz 1980), or negative (Schneider 1978) results.

Here in the Kommos case it can be seen that calcareous pottery fired at temperatures around $950^{\circ} \mathrm{C}$, where extensive vitrification develops, is affected preferentially by the leaching of all alkalis. It seems that the leaching is higher for $\mathrm{K}$ and $\mathrm{Na}$, than for $\mathrm{Rb}$ and $\mathrm{Cs}$. The similar behaviour of $\mathrm{Rb}$ and $\mathrm{Cs}$ is reflected in their $\tau_{\mathrm{Cs} . \mathrm{Rb}}$ value (0.0797) which is the lowest of all the $\tau$ values of both $\mathrm{Rb}$ and $\mathrm{Cs}$, when paired with the rest of the elements. The $\tau$ values with $\mathrm{Na}$ are not as low, due to the enrichment of some of the individuals with analcime, which compensates for any leaching of $\mathrm{Na}$. The process involved in that type of leaching is still not well understood, and no compensation has been found in any other major or minor element determined that would suggest chemical exchange. Even so, it is important to note that fine pottery (Group 1) was affected to a much greater extent than the medium coarse pottery (Group 2) of the assemblage under study. In Group 1 category 'D and I-M', 8 out of the 16 analysed individuals seem to be affected, while in Group 2 category ' $D$ and I-M', the number decreases to 3 out of 14 . Thus fine fabrics may be more susceptible to chemical action, in comparison to coarser examples fired at the same temperature, due the larger total active grain surface that they exhibit. It should also be noted that in calcareous pottery at temperatures above $850-900{ }^{\circ} \mathrm{C}$, the decomposition of the primary phases is quite advanced and at the same time the firing phases start to crystallize. Some of the latter, though, are metastable and could favour these kind of alterations. 
In the final case, all individuals allocated to Group 1 category ' $\mathrm{Cl}$ ' (low fired) exhibit higher relative values of Cs, which clearly points to enrichment in that element. No references demonstrating this phenomenon directly have been found in the archaeometric literature. The most relevant is a report for $\mathrm{Cs}$ and $\mathrm{Rb}$ fixation to compensate for loss of K (Lemoine et al. 1981) which, however, occurred in calcareous overfired ceramics. The adsorption of $\mathrm{Cs}$ in the low fired (below $750{ }^{\circ} \mathrm{C}$ ) ceramics studied is likely to be related to the high cation exchange capacity that low fired pottery exhibits (Hedges and McLellan 1976). Such an observation should be combined with the fact that Cs sorption capacity in clays, and especially in illites, is much greater than for the rest of the alkalis (Gauddette et al. 1966). In the ceramics which display an enrichment of Cs, illite is present due to the low firing temperature. Furthermore, another parameter that supports the above assumption is related to the role of the hydrated ionic radius of alkalis. The alkali metals are known to be soluble and at the same time easily hydrated. Therefore, instead of the ionic radius being the controlling factor for their sedimentary cycles, it is the radius of the hydrated ion that should be taken into consideration (Welby 1958). The order of increase in size of the hydrated ions is the reverse of the non-hydrated and in that respect the hydrated radius of Cs is the smallest (Boyd et al. 1947). According to this, Cs can move easily from the environment into the buried pottery, especially when intact illite is present in the ceramic.

The evidence discussed above demonstrates that three main distinct alteration and contamination processes have taken place in the Kommos Kiln samples that belong to petrographic Groups 1 to 3. It has been shown that those different processes are 
generally related to the level of the firing temperatures. However, not all individuals belonging to a given category are affected in the same way. These two observations seem to show that several other factors contribute to alteration processes such as, for example, the exact conditions of burial environment. Despite that, the present data are appropriate for an understanding of the general trends.

\section{Re-interpreting the original chemical clusters}

The presence of these alteration and contamination processes result in the perturbation of the initial compositional vectors (Buxeda 1999) and, as has already been shown, creates a complex structure in the chemical data giving five main Groups (Figure 1). It is apparent that the structure in the dendrogram and the existence of those clusters and subgroups is related not only to different raw materials of different provenance, but to perturbations produced by alteration and contamination processes during burial.

Therefore, a new cluster analysis was performed using CLUSTAN on the subcomposition $\mathrm{Sm}, \mathrm{Lu}, \mathrm{Yb}, \mathrm{Ce}, \mathrm{Cr}, \mathrm{Hf}, \mathrm{Sc}, \mathrm{Fe}, \mathrm{Eu}, \mathrm{La}$, thus excluding the affected elements. Again the variables were expressed as logratios over the concentration of La, as this transformation has been shown elsewhere to remove the indirect perturbations that exist even in the unaffected elements (Buxeda 1999). Using the square mean euclidean distance and the centroid algorithm, the dendrogram now shows a far more simple structure (Figure 8). All the individuals are placed in two different groups, which correspond to the petrographic Groups 1 to 4 , on the one hand, and 5 and 6, on the other. Only individuals KOM8 and 21 are not well grouped. The new dendrogram reflects the existence of one reference group, which includes petrographic Groups 1 to 4. The rest exhibit different chemical compositions as they are ceramics made from 
different raw materials. In fact, those groups are low calcareous and several differences are easily observed in the composition of major and minor elements by XRF. The high $\mathrm{Na}_{2} \mathrm{O}$ content is not related to any of the previously described processes, but to a higher content in sodic plagioclase.

Following the above, it is clear that the total variation value of 0.60 in the initial variation matrix (Table 1) had been affected by both the perturbation problems and by the existence of at least two broad different chemical compositions (Groups 1 to 4 vs. Groups 5 and 6). The problem can be controlled by the exclusion of Groups 5 and 6 from the calculation of a new variation matrix, as they represent different clays. The total variation obtained (Table 3 ) is now 0.54 which, although clearly lower than before, is still affected by the alteration and contamination processes. In order to avoid such influence, a third variation matrix was calculated, by excluding the original chemical Clusters B, D and E, as well as the outlier KOM40. The resulting variation matrix exhibits a lower total variation of 0.36 (Table 3). Another way to establish the effect of such alteration and perturbation processes is through a fourth variation matrix including all individuals in Groups 1-4, but excluding the elements involved ( $\mathrm{Na}, \mathrm{Rb}$ and $\mathrm{Cs}$ ). In this, the total variation decreased down to the value of 0.22 (Table 3). Estimating a mean value for each cell from the former variation matrix, we can now calculate the total variation, including the alkali elements whose variability could be approximated by this mean value. The total variation appears to be 0.27 (Table 3). Therefore, we can propose as a hypothesis that the original value of total variation was between the two values obtained ( 0.36 and 0.27$)$, something that can be clearly related to a monogenic cluster and considered as a reference group (Buxeda and Kilikoglou in press). 
An obvious question raised by the above discussion is whether such alterations and perturbations can be detected and accounted for in the cases of the pottery coming from a consumption assemblage, such as a settlement, without knowledge of their integrity as a production group. In such cases there are no pre-assumptions about the expected level of chemical homogeneity and therefore variability cannot easily be judged against any parameters which might guide us. Thus it becomes necessary to combine chemical analysis with other techniques that provide mineralogical and technological information, to form an integrated whole in order to suggest which individuals realistically might comprise production groups.

\section{Conclusions}

This study has shown that, under specific conditions, serious alteration and contamination processes may take place and alter significantly the chemical compositions of pottery. This is so even in the case of pottery from an individual kiln site, complicating the production of a reference group from the very material assumed, by most approaches to chemical provenance, to be the most reliable. The presence of a range of firing temperatures might be expected from a kiln site, especially from a dump containing rejected pottery. As many of the alterations we discuss are related to very low and over-fired calcareous ceramic bodies, we might suggest that pottery from kiln sites in fact needs special attention when it is used in the formation of reference groups.

In the case of the Kommos Kiln, three different types of selective alterations have been detected, each of them acting independently but all contributing significantly 
to the overall alteration process. The type of alteration that each individual sample has undergone depends greatly on the original chemical composition, as well as to the microstructure and the mineral phases developed during firing. The other important parameter for alterations is the burial environment.

In the Kommos pottery analysed in this study there were three types of alterations found, all related to the calcareous nature of pottery:

- Adsorption of Cs in very low fired fine pottery (no vitrification and presence of chlorite).

- Leaching of alkalis in pottery fired at temperatures where extensive vitrification is developed. This affects the fine grained pottery preferentially. - Leaching of $\mathrm{K}$ and $\mathrm{Rb}$ from the altered glassy phase in very highly fired and overfired pottery with the subsequent enrichment of $\mathrm{Na}$ due to the crystallization of analcime.

Therefore, it becomes evident that chemical variability in pottery should be explored by means of a combination of mineralogical and microscopic techniques in order to identify the causes and attribute the variability to either provenance/technology or possible alterations. Taking into consideration the alteration processes and controlling the effects on the chemical compositions, it is possible to characterise pottery and, in the case of a kiln, confidently to form a reference group. In this manner, in the case of a consumption assemblage, we may proceed to assign provenance to such groups.

Through such an integrated approach, at Kommos it was possible to characterise chemically the reference group for the calcareous LMIA pottery from the kiln, in concordance with the petrographic grouping, and to establish in this way a reliable reference group for the products of that kiln. 


\section{Acknowledgements}

We would like warmly to thank Joseph W. Shaw for providing the opportunity to become involved with the Kommos kiln pottery and Aleydis van der Moortel for advising on sampling and many other aspects of the kiln assemblage. We are grateful to the $23^{\text {rd }}$ Ephorate of Classical and Prehistoric Antiquities in Herakleion and to the Directorate of Conservation of the Ministry of Culture, Greece for permission to sample and analyse the material.

We are also indebted to Alexandra Tsolakidou and Eddy Faber for their help in NAA and SEM analyses, to Louise Joyner for petrographic analysis and to Miguel Angel Cau Ontiveros for his help in some XRF analyses.

Initial neutron activation and petrographic analyses were funded by a grant to the Kommos Excavations from the Institute for Aegean Prehistory. The work presented here forms part of the GEOPRO Research Network funded by DGXII of the European Commission, under the Training and Mobility of Researchers Network Programme (Contract number ERBFMRX-CT98-0165). We are indeed most grateful to TMR in the European Commission for the funding which enables our collaborative work.

\section{Bibliography}

Aitchinson, J., 1986, The Statistical Analysis of Compositional Data, Chapman and Hall, London. 
Aitchinson, J., 1990, Relative Variation Diagrams for Describing Patterns of Compositional Variability, Mathematical Geology, 22, 487-511.

Arnold, D.E., 1992, Comments on Section II, in Chemical Characterisation of Ceramic Pastes in Archaeology (ed. H. Neff), Monographs in World Archaeology, 7, 107- 34, Prehistory Press, Madison, Wisconsin.

Asaro, F., Michel, H., Widemann, F., and Fillières-Kunetz, D., 1975, Étude analytique de la provenance d'un vase signé C. CIN() SENOVIRI trouvé à Salelles, Le Bosc (Hérault), Gallia, 33, 225-8.

Bishop, R.L., Rands, R.L., and Holley, G., 1982, Ceramic Compositional Analysis in Archaeological Perspective, in Advances in Archaeological Method and Theory (ed. M.B. Schiffer), 5, 275-330, Academic Press, New York.

Boyd, G.E., Schubert, J., and Adamson, A.W., 1947, Ion-exchanged equilibria on the ion exchange resins, Journal of the American Chemical Society, 69, 2818-29.

Buxeda i Garrigós, J., 1999, Alteration and contamination of archaeological ceramics: The perturbation problem, Journal of Archaeological Science, 26, 295-313.

Buxeda i Garrigós, J., Cau Ontiveros, M.A., 1997, Caracterización arqueométrica de las ánforas “T-8.1.3.1.” del taller púnico "FE-13” (Eivissa), appendix in FE-13. Un taller alfarero de época púnica en Ses Figueretes (Eivissa), (J. Ramón Torres), 
Trabajos del Museo Arqueológico de Eivissa, 39, Govern Balear, Concellaria d' Educació, Cultura i Esports 179-203, Eivissa.

Buxeda i Garrigós, J., and Kilikoglou, V., in press, Total variation as a measure of variability in chemical data sets, in Patterns and Process (eds. L. van Zelst, R.L. Bishop and J. Henderson), Smithsonian Institution, Washington D.C.

Catling, H.W., Cherry, J.F., Jones, R.E. and Killen, J.T., 1980, The inscribed stirrup jars and West Crete, Annual of the British School at Athens, 75, 49-113.

Day, P.M. and Haskell, H.W., 1995, Transport stirrup jars as indicators of trade and production in the Late Bronze III Aegean, in Trade and Production in Premonetary Greece: aspects of trade, (eds. C. Gillis and C. Risberg), 87-109, Studies in Mediterranean Archaeology and Literature, Jonsered.

Day, P.M., Kiriatzi, E., Tsolakidou, A., and Kilikoglou, V., 1999, Group Therapy: A comparison between analyses by NAA and thin section petrography of Early Bronze Age pottery from Central and East Crete, Journal of Archaeological Science, 26, 1025 36.

Day, P.M. and Wilson, D.E., 1998, Consuming power: Kamares Ware in Protopalatial Knossos, Antiquity, 72, 350-8. 
Fillières, D., Harbottle, G., and Sayre, E.V., 1983, Neutron Activation Study of Figurines, Pottery, and Workshop Materials from the Athenian Agora, Greece, Journal of Field Archaeology, 10, 55-69.

Gaudette, H.E., Grim, R. E., and Metzger, C.F., 1966, Illite: A model based on the sorption behavior of Caesium, The American Mineralogist, 51, 1649-56.

Harbottle, G., 1982, Chemical characterization in Archaeology, in Contexts For Prehistoric Exchange (ed. J.E. Ericson), 13-51, Academic Press.

Hedges, R.E.M., and McLellan, M., 1976, On the cation exchange capacity of fired clays and its effect on the chemical and radiometic analysis of pottery, Archaeometry, 18, 203-7.

Heiman, R.B., 1982, Firing technologies and their possible assessment by modern analytical methods, in Archaeological Ceramics (eds. J.S. Olin, A.D. Franklin), 89-96, Smithsonian Institution Press, Washington D.C.

Heimann, R.B., and Maggetti, M., 1981, Experiments on simulated burial calcareous Terra Sigillata (mineralogical change). Preliminary results, in Scientific studies in ancient ceramics (ed. M.J. Hughes), 163-77, British Museum Occasional Paper, 19, London.

Jones, R.E., 1986, Greek and Cypriot pottery: a review of scientific studies, The British School at Athens, Fitch Laboratory Occasional Paper, 1, Athens. 
Jornet, A., 1982, Analyse minéralogique et chimique de la céramique romaine suisse à enduit brillant, Institut de Minéralogie et Pétrographie de l’Université Fribourg/Suisse, Thèse n. 846, Fribourg.

Kilikoglou, V., 1994, 'Scanning Electron Microscopy', in D.E. Wilson and P.M. Day, Ceramic Regionalism in Prepalatial Central Crete: The Mesara Imports at EMI to EMIIA Knossos, Annual of the British School at Athens, 89, 1-87.

Kilikoglou, V., Maniatis, Y., and Grimanis, A.P., 1988, The Effect of Purification and Firing of Clays on Trace Element Provenance studies, Archaeometry, 30, 37-46.

Lemoine, C., Meille, E., Poupet, P., Barrandon, J.N., and Borderie, B., 1981, Étude de quelques altérations de composition chimique des céramiques en milieu marin et terrestre, Revue d'Archéometrie, Suppl. S, 349-60.

Maggetti, M., 1981, Composition of roman pottery from Lousonna (Switzerland), in Scientific studies in ancient ceramics (ed. M.J. Hughes), 33-49, British Museum Occasional Paper, 19, London.

Maggetti, M., 1982, Phase analysis and its significance for technology and origin, in Archaeological Ceramics (eds. J.S. Olin, A.D. Franklin), 121-33, Smithsonian Institution Press, Washington D.C. 
Maniatis, Y., and Tite, M.S., 1981, Technological examination of Neolithic-Bronze Age pottery from Central and Southeast Europe and from the Near East, Journal of Archaeological Science, 8, 59-76.

Maniatis, Y., Whitebread, I.K., Jones, R.E., Simopoulos, A., Kostikas, A., and Williams, C.K., 1984, Punic Amphoras found at Corinth, Greece: an investigation of their provenance and technology, Journal of Field Archaeology, 11, 205-22.

Myer, G.H. and Betancourt, P.P., 1990, The fabrics at Kommos, in P.P. Betancourt, Kommos II. The final neolithic through Middle Minoan III pottery, 1-13, Princeton, Princetone University Press.

Neff, H., Bishop, R.L., and Sayre, E.V., 1988, A simulation approach to the problem of tempering in compositional studies of archaeological ceramics, Journal of Archaeological Science, 15, 159-72.

Olin, J.S., Harbottle, G., and Sayre, E.V., 1978, Elemental Compositions of Spanish and Spanish-Colonial Majolica Ceramics in the Identification of Provenience, in Archaeological Chemistry II (ed. G.F. Carter), 200-29, Advances in Chemistry Series, 171, American Chemical Society, Washington D.C.

Picon, M., 1976, Remarques préliminaires sur deux types d'altération de la composition chimique des céramiques au cours du temps, Figlina, 1, 159-66. 
Picon, M., 1991, Quelques observations complementaires sur les altérations de composition des céramiques aur cours du temps: cas de quelques alcalins et alcalino-terreux, Revue d'Archéometrie, 15, 117-22.

Riley, J.A., 1983, The contribution of ceramic petrology to our understanding of Minoan Society, in Minoan Society (eds. O. Krzyskowska and L. Nixon), 283-92, Bristol Classical Press, Bristol.

Sayre, E.V., Chan, L-H., and Sabloff, J.A., 1971, High-Resolution gamma Ray Spectroscopic Analyses of Mayan Fine Orange Pottery, in Science in Archaeology (ed. R.H. Brill), 165-81, The MIT Press, Cambridge, Massachusetts.

Schmitt, A., 1989, Méthodes géochimiques, pétrographiques et minéralogiques appliquées à la détermination de l'origine des céramiques archéologiques, Thèse de Doctorat, Université de Bordeaux III, Bordeaux.

Schneider, G., 1978, Anwendung quantitativer Materialanalysen auf Herkunftsbestimmungen antiker Keramik, Berliner Beiträge zur Archäometrie, 3, 63-122.

Segebade, C., and Lutz, G.J., 1980, Photon activation analysis of ancient Roman pottery, in Proceedings of the $16^{\text {th }}$ International Symposium on Archaeometry and Archaeological Prospection (Edimburgh, 1976) (eds. E.A. Slater and J.O. Tate), 20-49, National Museum of Antiquities of Scotland. 
Shaw, J., Van de Moortel, A., Day, P.M., and Kilikoglou, V., 1997, A LM IA Pottery Kiln at Kommos, Crete, in TEXNH: Craftsmen, Craftswomen and Craftsmanship in the Aegean Bronze Age (eds. R. Laffineur and P.P. Betancourt), 323-31, Aegaeum, 16, Liège.

Shaw, J., Van de Moortel, A., Day, P.M., and Kilikoglou, V., 2001, A LM IA Ceramic Kiln in South-Central Crete: Function and Pottery Production, Hesperia supplement 30, Princeton.

Shepard, A.O., 1936, The technology of Pecos Pottery, in The Pottery of Pecos (eds. A.V. Kidder and A.O. Shepard), 389-587, Vol. 2, Papers of the Phillips Academy Southwestern Expedition, 7, Yale University Press, New Haven Conn.

Walter, V., 1988, Étude pétrographique, minéralogique et géochimique d'amphores gauloises découvertes dans le Nord-Est de la France, Thèse de Doctorat, Université des Sciences Humaines de Strasbourg, U.F.R. des Sciences Historiques, CNRS - Centre de Sédimentologie et de Géochimique de la Surface, Strasbourg.

Weigand, P.C., Harbottle, G., and Sayre, E.V., 1977, Turquoise sources and source analysis: Mesoamerica and the Southwestern U.S.A., in Exchange systems in prehistory (eds. T.K. Earle and J.E. Ericson), 15-34, Academic Press. 
Welby, C.W., 1958, Occurence of alkali metals in some Gulf of Mexico Sediments, Journal of Sedimentary Petrology, 28, 431-52.

Whitelaw, T.M., Day, P.M., Kiriatzi, E., Kilikoglou, V and Wilson, D.E., 1997, Ceramic traditions at EMIIB Myrtos, Fournou Korifi, in TEXNH: Craftsmen, Craftswomen and Craftsmanship in the Aegean Bronze Age (eds. R. Laffineur and P.P. Betancourt), 265-74, Aegaeum 16, Liège and Austin, Texas.

Wilson, D.E. and Day, P.M., 1994, Ceramic Regionalism in Prepalatial Central Crete: The Mesara Imports at EMI to EMIIA Knossos, Annual of the British School at Athens, 89, 1-87 


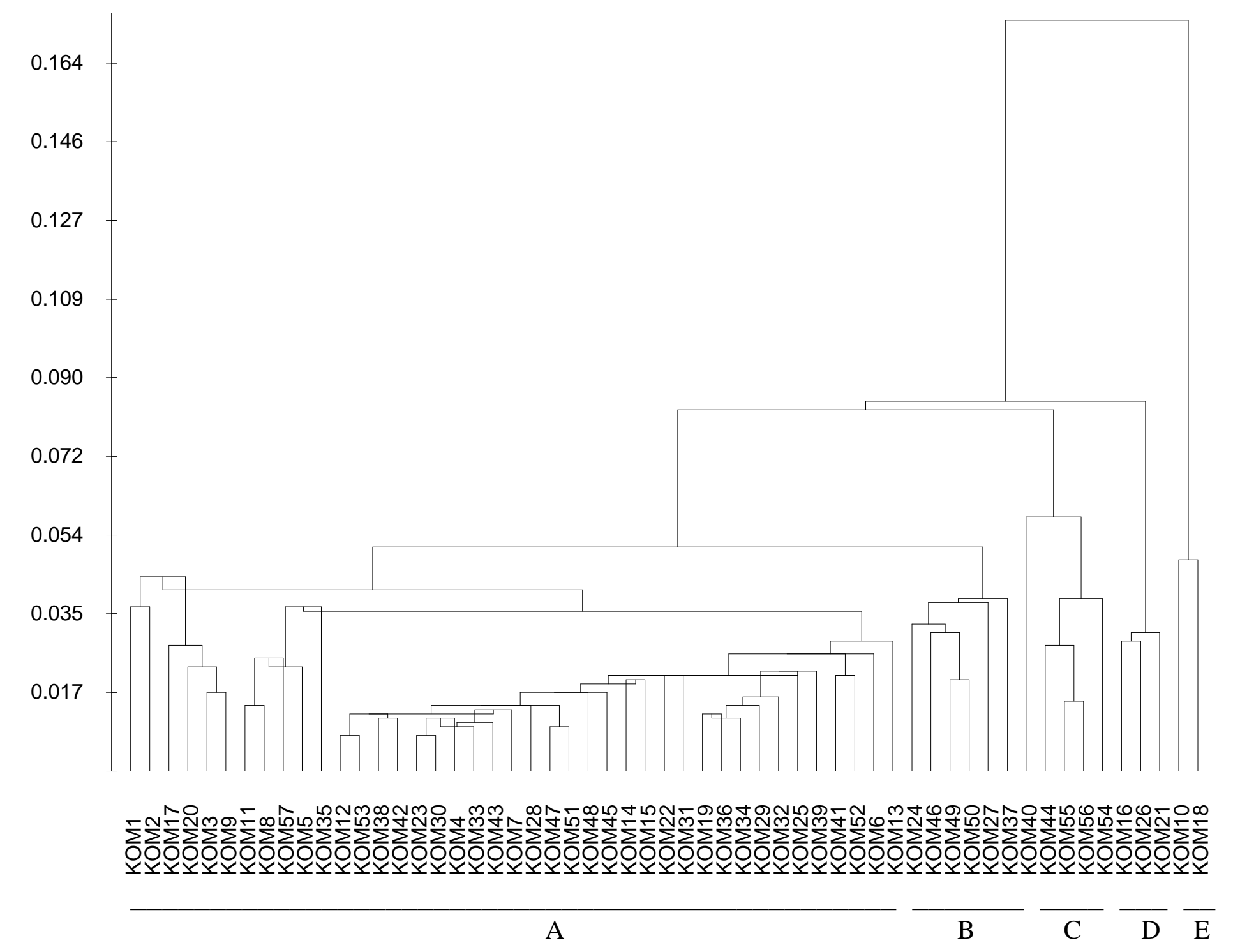

Figure 1. Cluster analysis dendrogram on subcomposition Sm, Lu, U, Yb, Ca, Na, Ce, Cr, Hf, Cs, Sc, Rb, Fe, Eu and La which is used as a divisor in logratio transformation. 


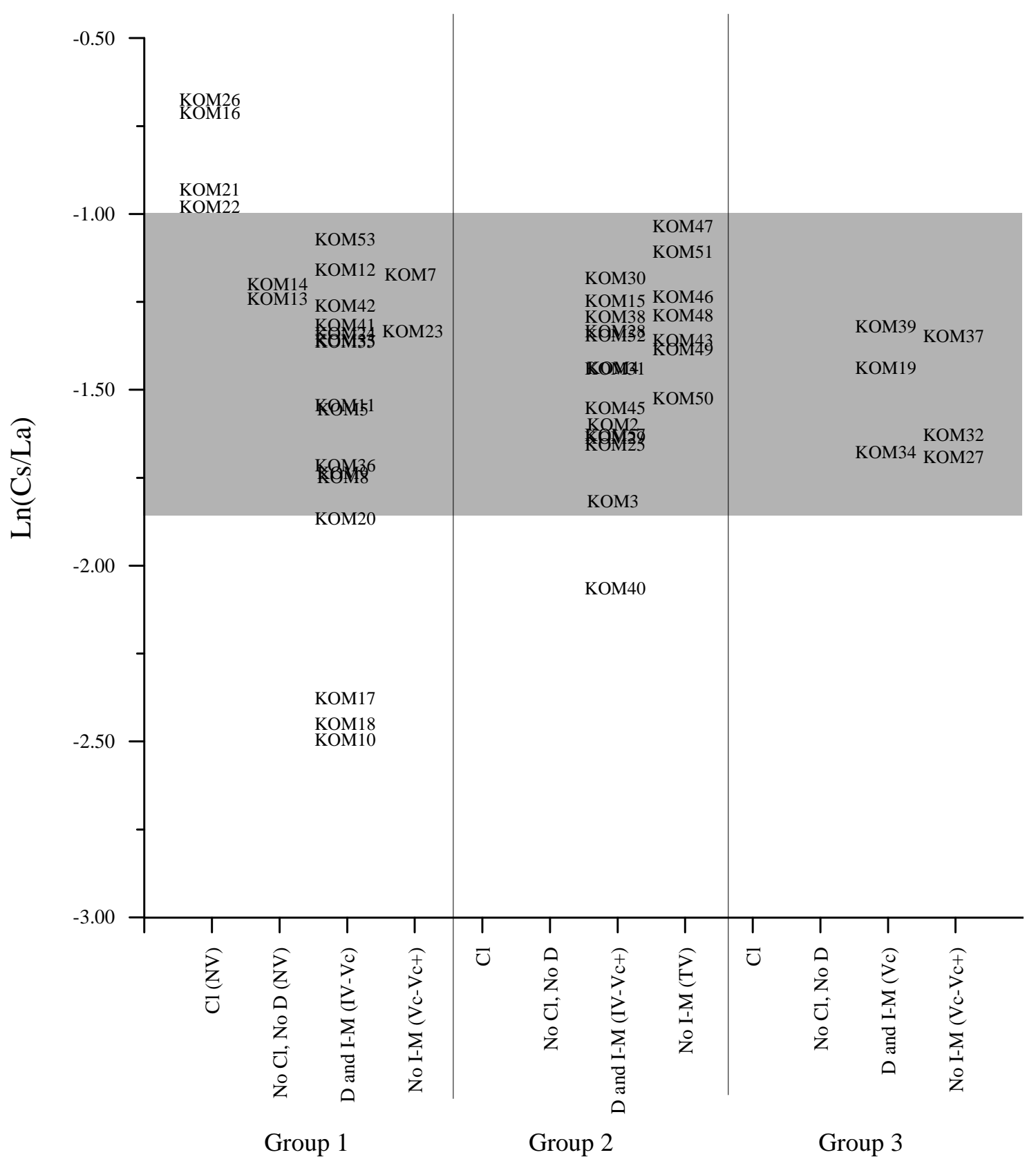

Categories of association of crystalline phases by XRD

Figure 2. Bivariate plot of XRD crystalline phases' categories (for petrographic groups 1,2 and 3) versus $\ln (\mathrm{Cs} / \mathrm{La})$ values. (NV=No vitrification, IV=Initial vitrification, $\mathrm{V}_{\mathrm{c}}=$ Extensive vitrification, $\mathrm{V}_{\mathrm{c}+}=$ Advanced vitrification, $\mathrm{TV}=$ Total vitrification). 


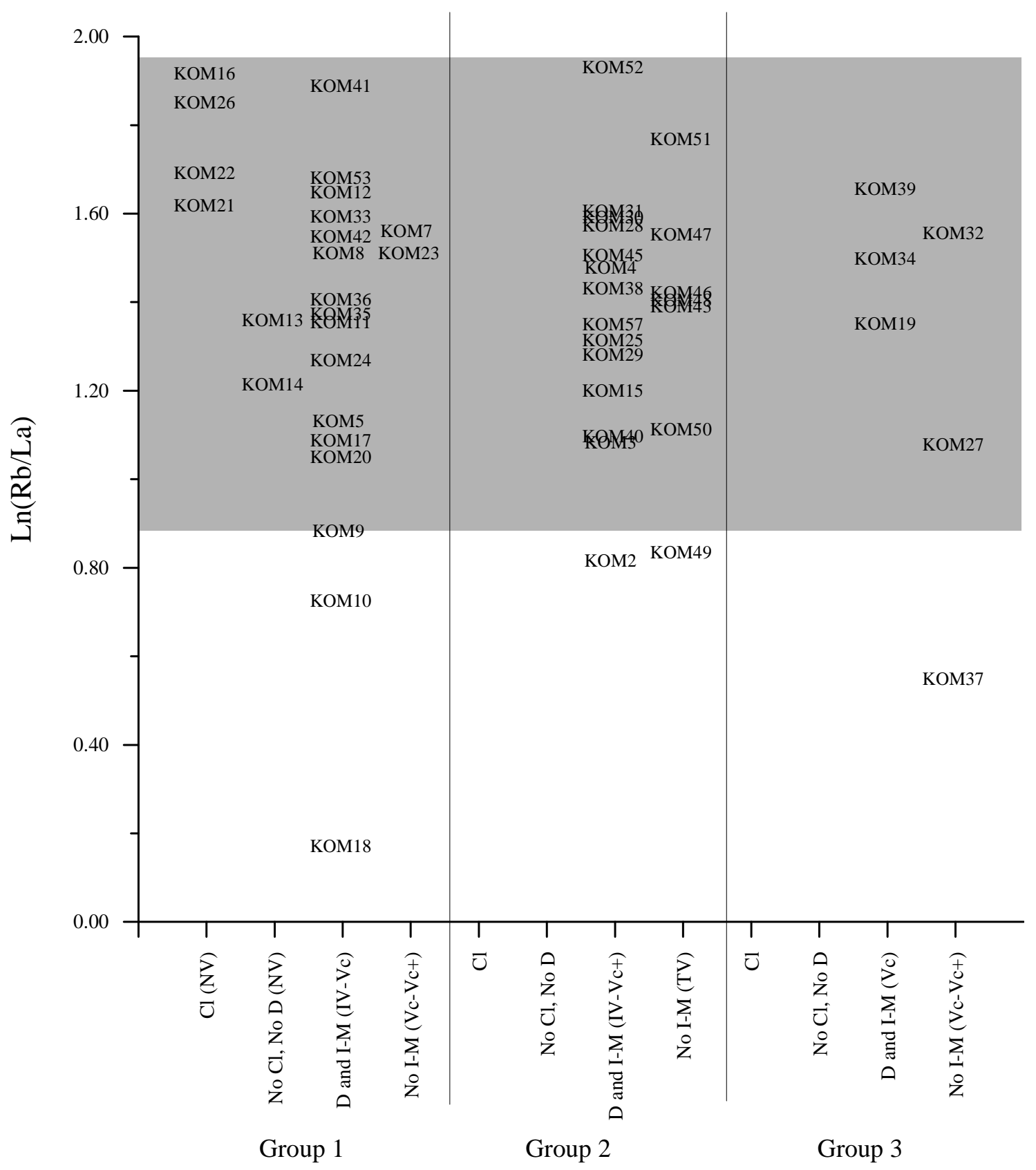

Categories of association of crystalline phases by XRD

Figure 3. Bivariate plot of XRD crystalline phases' categories (for petrographic groups 1, 2 and 3) versus $\ln (\mathrm{Rb} / \mathrm{La})$ values. ( $\mathrm{NV}=$ No vitrification, $\mathrm{IV}=$ Initial vitrification, $\mathrm{V}_{\mathrm{c}}=$ Extensive vitrification, $\mathrm{V}_{\mathrm{c}+}=$ Advanced vitrification, $\mathrm{TV}=$ Total vitrification). 


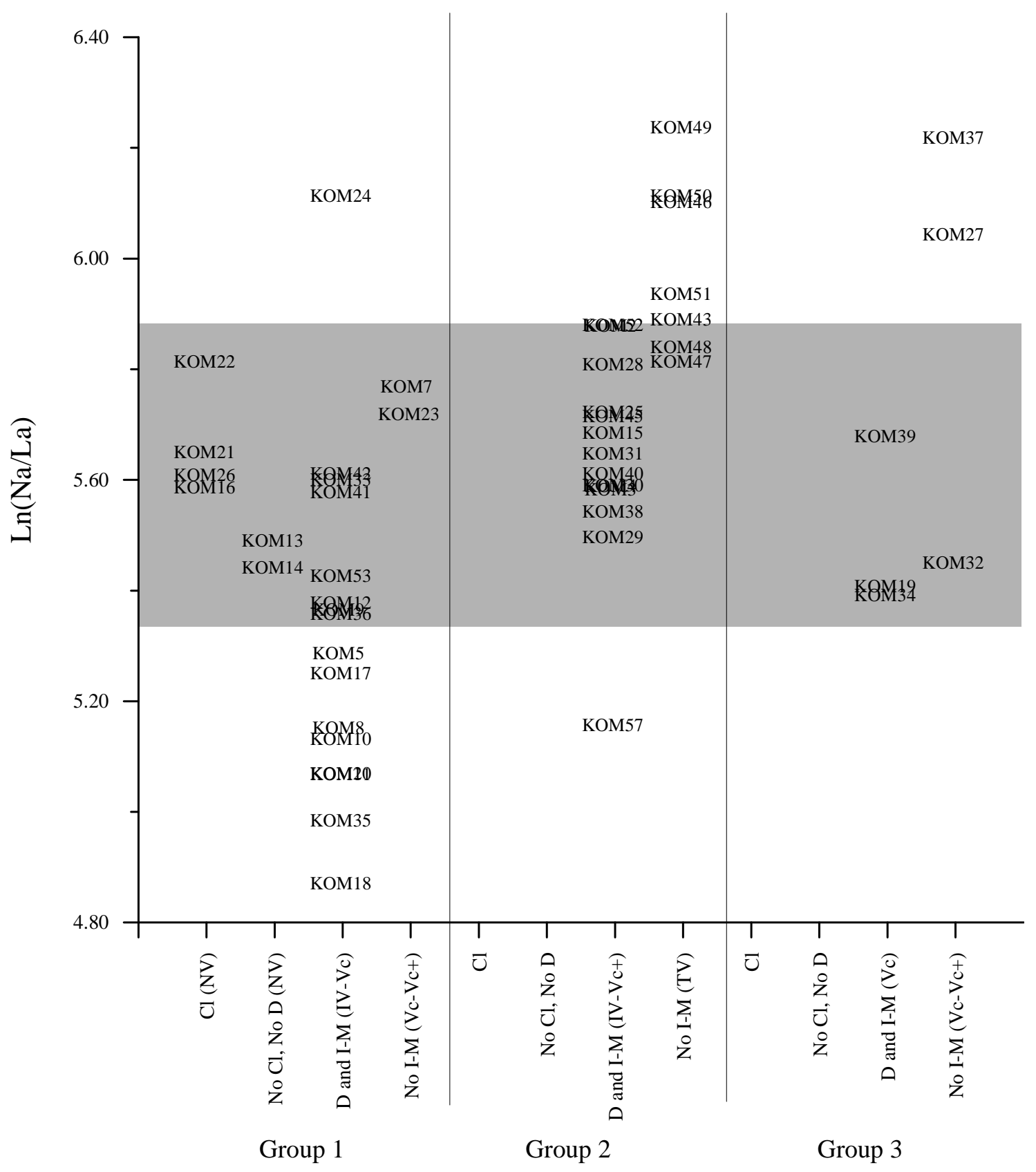

Categories of association of crystalline phases by XRD

Figure 4. Bivariate plot of XRD crystalline phases' categories (for petrographic groups 1, 2 and 3) versus $\ln (\mathrm{Na} / \mathrm{La})$ values. ( $\mathrm{NV}=$ No vitrification, $\mathrm{IV}=$ Initial vitrification, $\mathrm{V}_{\mathrm{c}}=$ Extensive vitrification, $\mathrm{V}_{\mathrm{c}+}=$ Advanced vitrification, $\mathrm{TV}=$ Total vitrification). 


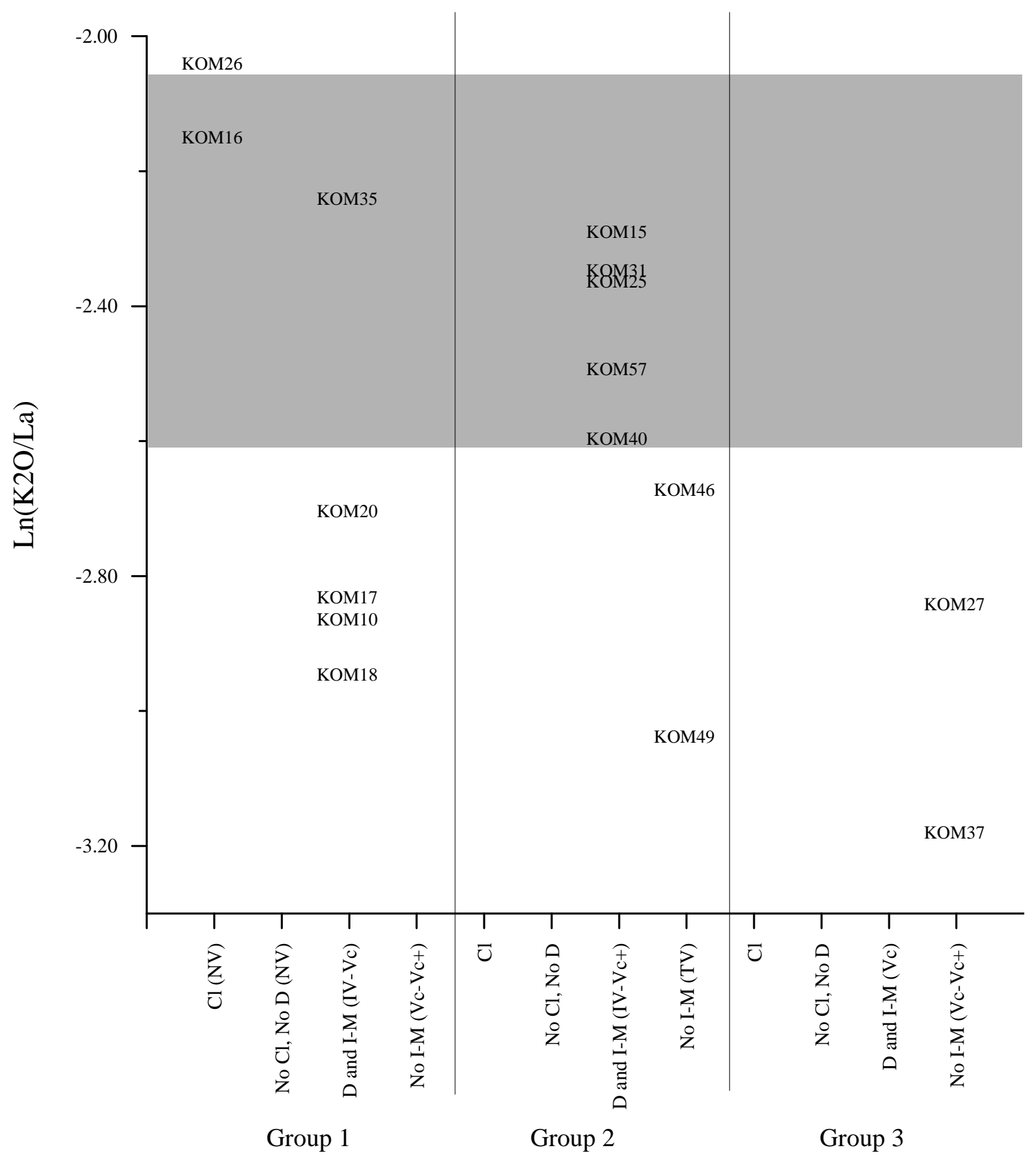

Categories of association of crystalline phases by XRD

Figure 5. Bivariate plot of XRD crystalline phases' categories (for petrographic groups 1, 2 and 3) versus $\ln \left(\mathrm{K}_{2} \mathrm{O} / \mathrm{La}\right)$ values. ( $\mathrm{NV}=$ No vitrification, $\mathrm{IV}=$ Initial vitrification, $\mathrm{V}_{\mathrm{c}}=$ Extensive vitrification, $\mathrm{V}_{\mathrm{c}+}=$ Advanced vitrification, $\mathrm{TV}=$ Total vitrification) . 


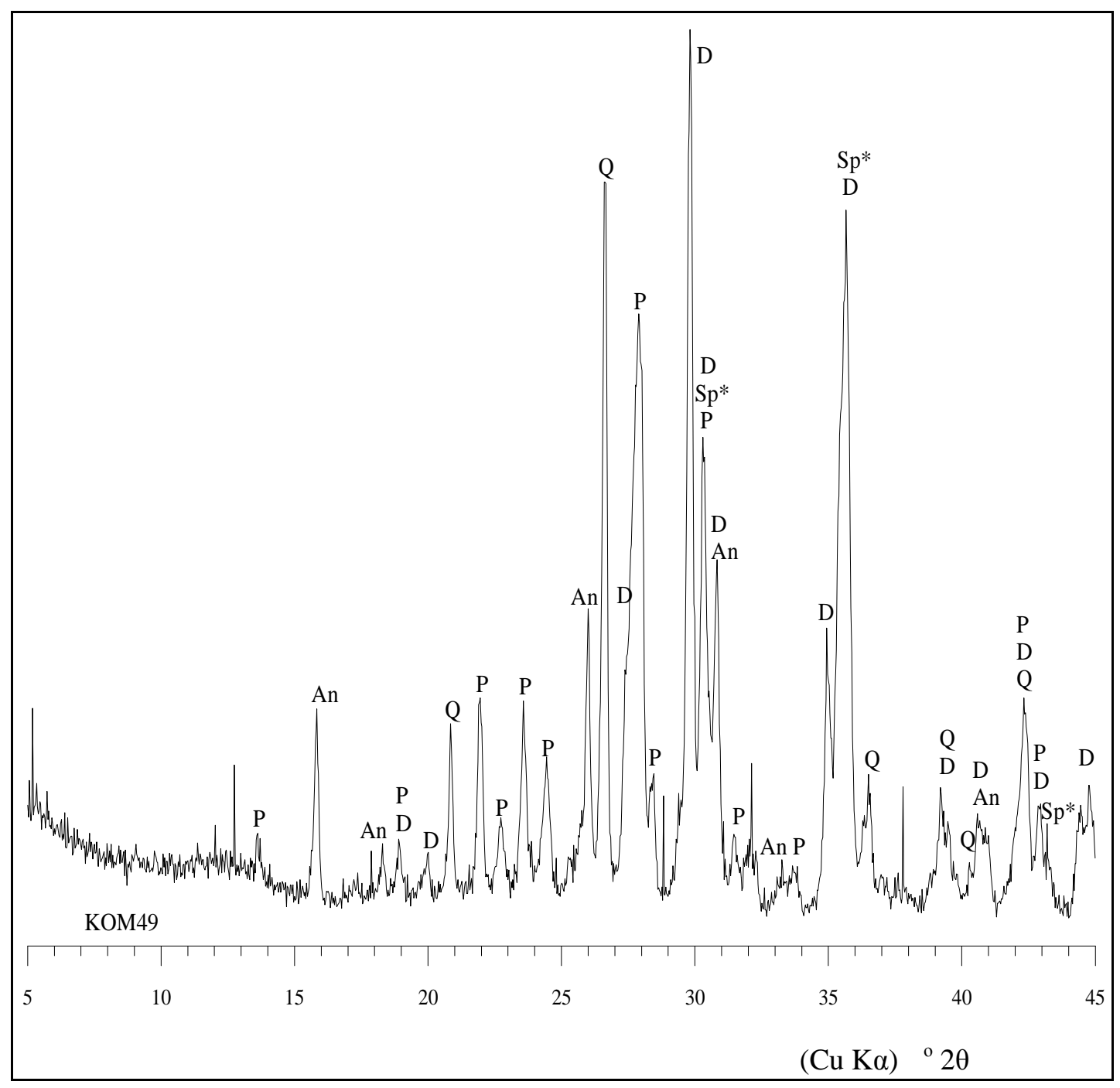

Figure 6. Diffractogram of individual KOM49 (Q: quartz; D: pyroxene; P: plagioclase; Sp*: spinel type; An: analcime). 


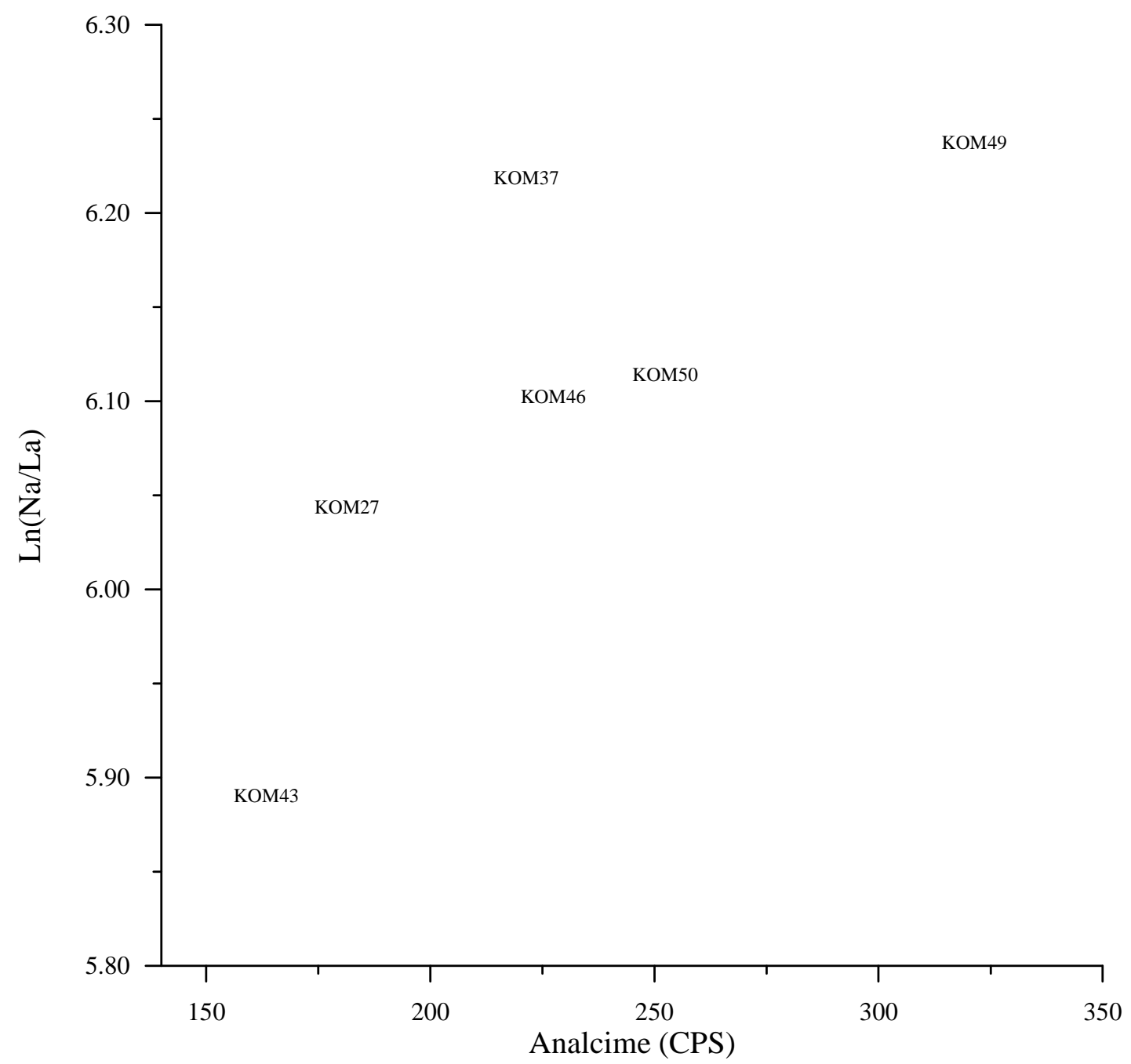

Figure 7. Bivariate plot of $5.59 \AA$ analcime peak (in counts per second, CPS) versus $\ln (\mathrm{Na} / \mathrm{La})$ values 


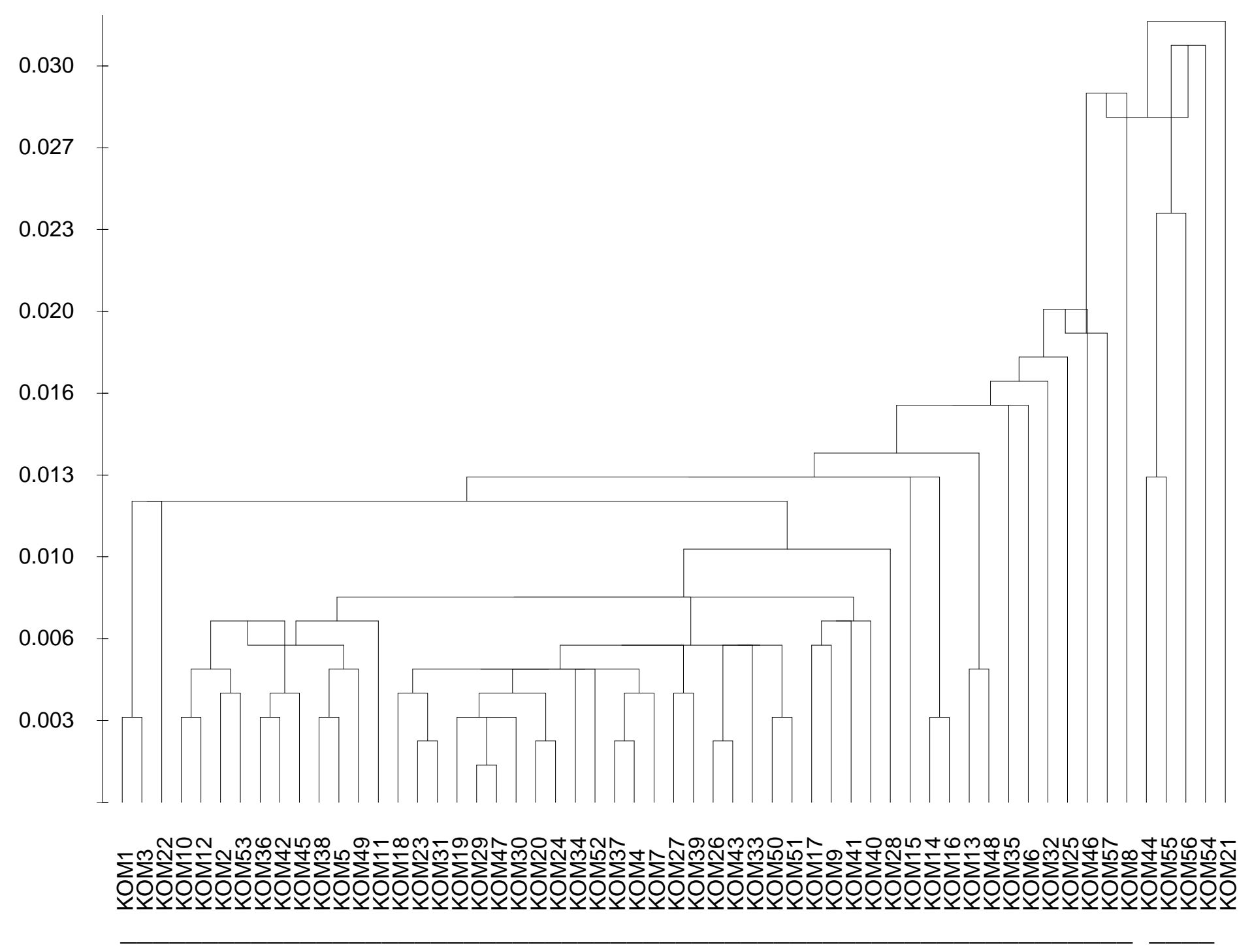

1 to 4

Figure 8. Cluster analysis dendrogram on subcomposition $\mathrm{Sm}, \mathrm{Lu}, \mathrm{Yb}, \mathrm{Ce}, \mathrm{Cr}, \mathrm{Hf}, \mathrm{Sc}, \mathrm{Fe}, \mathrm{Eu}$ and $\mathrm{La}$ which is used as a divisor in logratio transformation) 


\begin{tabular}{|c|c|c|c|c|c|c|c|c|c|}
\hline & $\mathrm{Sm}$ & $\mathrm{Lu}$ & $\mathrm{U}$ & $\mathrm{Yb}$ & $\mathrm{Ca}$ & $\mathrm{Na}$ & $\mathrm{La}$ & $\mathrm{Ce}$ & Th \\
\hline $\mathrm{Sm}$ & 0 & 0.01515 & 0.05836 & 0.01309 & 0.14008 & 0.09878 & 0.00844 & 0.01815 & 0.0201 \\
\hline $\mathrm{Lu}$ & 0.01515 & 0 & 0.04862 & 0.01333 & 0.13684 & 0.11282 & 0.01104 & 0.02183 & 0.01962 \\
\hline $\mathrm{U}$ & 0.05836 & 0.04862 & 0 & 0.04628 & 0.12242 & 0.1562 & 0.04311 & 0.06523 & 0.04795 \\
\hline $\mathrm{Yb}$ & 0.01309 & 0.01333 & 0.04628 & 0 & 0.15294 & 0.11128 & 0.00619 & 0.01188 & 0.01441 \\
\hline $\mathrm{Ca}$ & 0.14008 & 0.13684 & 0.12242 & 0.15294 & 0 & 0.25104 & 0.12601 & 0.14769 & 0.132 \\
\hline $\mathrm{Na}$ & 0.09878 & 0.11282 & 0.1562 & 0.11128 & 0.25104 & 0 & 0.11856 & 0.12773 & 0.16218 \\
\hline $\mathrm{La}$ & 0.00844 & 0.01104 & 0.04311 & 0.00619 & 0.12601 & 0.11856 & 0 & 0.00857 & 0.00719 \\
\hline $\mathrm{Ce}$ & 0.01815 & 0.02183 & 0.06523 & 0.01188 & 0.14769 & 0.12773 & 0.00857 & 0 & 0.01235 \\
\hline Th & 0.0201 & 0.01962 & 0.04795 & 0.01441 & 0.132 & 0.16218 & 0.00719 & 0.01235 & \\
\hline $\mathrm{Cr}$ & 0.02756 & 0.0315 & 0.0711 & 0.02161 & 0.13713 & 0.16667 & 0.01588 & 0.0177 & 0.01405 \\
\hline $\mathrm{Hf}$ & 0.02866 & 0.03357 & 0.07446 & 0.01495 & 0.19517 & 0.12972 & 0.02233 & 0.02245 & 0.03114 \\
\hline Cs & 0.13873 & 0.14442 & 0.17767 & 0.14226 & 0.29093 & 0.18308 & 0.13127 & 0.11997 & 0.12611 \\
\hline $\mathrm{Sc}$ & 0.01841 & 0.01587 & 0.05492 & 0.01273 & 0.12869 & 0.14068 & 0.00756 & 0.01098 & 0.00625 \\
\hline $\mathrm{Rb}$ & 0.12844 & 0.12455 & 0.15321 & 0.12152 & 0.30014 & 0.22219 & 0.11785 & 0.11668 & 0.11549 \\
\hline $\mathrm{Fe}$ & 0.01793 & 0.01537 & 0.05303 & 0.01064 & 0.13113 & 0.14314 & 0.00643 & 0.01039 & 0.00416 \\
\hline $\mathrm{Co}$ & 0.02204 & 0.02214 & 0.05792 & 0.01705 & 0.12404 & 0.15125 & 0.01027 & 0.01414 & 0.00618 \\
\hline $\mathrm{Eu}$ & 0.02537 & 0.02974 & 0.07759 & 0.01988 & 0.167 & 0.10112 & 0.02369 & 0.02633 & 0.0363 \\
\hline$\tau . \mathrm{i}$ & 0.77928 & 0.79639 & 1.30808 & 0.73004 & 2.68322 & 2.37644 & 0.66439 & 0.75204 & 0.75547 \\
\hline $\mathrm{vt} / \tau . \mathrm{i}$ & 0.7746 & 0.75796 & 0.46146 & 0.82685 & 0.22497 & 0.25401 & 0.90855 & 0.80265 & 0.79902 \\
\hline $\mathrm{r} v, \tau$ & 0.98119 & 0.9881 & 0.9381 & 0.98793 & 0.92191 & 0.84151 & 0.99288 & 0.99425 & 0.97877 \\
\hline
\end{tabular}

\begin{tabular}{|c|c|c|c|c|c|c|c|c|}
\hline & $\mathrm{Cr}$ & Hf & Cs & $\mathrm{Sc}$ & $\mathrm{Rb}$ & $\mathrm{Fe}$ & $\mathrm{Co}$ & $\mathrm{Eu}$ \\
\hline $\mathrm{Sm}$ & 0.02756 & 0.02866 & 0.13873 & 0.01841 & 0.12844 & 0.01793 & 0.02204 & 0.02537 \\
\hline $\mathrm{Lu}$ & 0.0315 & 0.03357 & 0.14442 & 0.01587 & 0.12455 & 0.01537 & 0.02214 & 0.02974 \\
\hline $\mathrm{U}$ & 0.0711 & 0.07446 & 0.17767 & 0.05492 & 0.15321 & 0.05303 & 0.05792 & 0.07759 \\
\hline $\mathrm{Yb}$ & 0.02161 & 0.01495 & 0.14226 & 0.01273 & 0.12152 & 0.01064 & 0.01705 & 0.01988 \\
\hline $\mathrm{Ca}$ & 0.13713 & 0.19517 & 0.29093 & 0.12869 & 0.30014 & 0.13113 & 0.12404 & 0.167 \\
\hline $\mathrm{Na}$ & 0.16667 & 0.12972 & 0.18308 & 0.14068 & 0.22219 & 0.14314 & 0.15125 & 0.10112 \\
\hline $\mathrm{La}$ & 0.01588 & 0.02233 & 0.13127 & 0.00756 & 0.11785 & 0.00643 & 0.01027 & 0.02369 \\
\hline $\mathrm{Ce}$ & 0.0177 & 0.02245 & 0.11997 & 0.01098 & 0.11668 & 0.01039 & 0.01414 & 0.02633 \\
\hline $\mathrm{Th}$ & 0.01405 & 0.03114 & 0.12611 & 0.00625 & 0.11549 & 0.00416 & 0.00618 & 0.0363 \\
\hline $\mathrm{Cr}$ & 0 & 0.04306 & 0.15527 & 0.01096 & 0.14003 & 0.01046 & 0.01064 & 0.04289 \\
\hline Hf & 0.04306 & 0 & 0.16403 & 0.03449 & 0.15084 & 0.03143 & 0.04011 & 0.03856 \\
\hline Cs & 0.15527 & 0.16403 & 0 & 0.12248 & 0.07971 & 0.1237 & 0.11939 & 0.13836 \\
\hline $\mathrm{Sc}$ & 0.01096 & 0.03449 & 0.12248 & 0 & 0.11284 & 0.00104 & 0.00218 & 0.0274 \\
\hline $\mathrm{Rb}$ & 0.14003 & 0.15084 & 0.07971 & 0.11284 & 0 & 0.11216 & 0.11115 & 0.1366 \\
\hline $\mathrm{Fe}$ & 0.01046 & 0.03143 & 0.1237 & 0.00104 & 0.11216 & 0 & 0.0017 & 0.0287 \\
\hline $\mathrm{Co}$ & 0.01064 & 0.04011 & 0.11939 & 0.00218 & 0.11115 & 0.0017 & 0 & 0.03365 \\
\hline $\mathrm{Eu}$ & 0.04289 & 0.03856 & 0.13836 & 0.0274 & 0.1366 & 0.0287 & 0.03365 & 0 \\
\hline$\tau . i$ & 0.91651 & 1.05496 & 2.35736 & 0.70746 & 2.2434 & 0.7014 & 0.74385 & 0.95316 \\
\hline $\mathrm{vt} / \tau . \mathrm{i}$ & 0.65862 & 0.57218 & 0.25606 & 0.85323 & 0.26907 & 0.86061 & 0.8115 & 0.6333 \\
\hline r v, $\tau$ & 0.97939 & 0.98504 & 0.5654 & 0.98823 & 0.66983 & 0.98856 & 0.97577 & 0.97345 \\
\hline
\end{tabular}

$\begin{array}{ll}\Sigma \tau . \mathrm{i} & 20.5234 \\ \mathrm{Vt} & 0.60363\end{array}$

Table 1. Variation matrix of the 57 individuals analysed by NAA 


\begin{tabular}{|c|c|c|c|c|c|}
\hline & $\mathrm{Na}$ (\%) & $\mathrm{K}_{2} \mathrm{O}$ (\%) & $\mathbf{R b}$ & $\mathrm{Cs}$ & La \\
\hline KOM01 & 0.68 & 2.05 & 45 & 4.60 & 23.75 \\
\hline KOM02 & 0.79 & & 53 & 4.47 & 22.05 \\
\hline KOM03 & 0.63 & & 66 & 3.85 & 23.71 \\
\hline KOM0 4 & 0.61 & & 105 & 5.42 & 22.83 \\
\hline KOM0 5 & 0.51 & & 82 & 5.45 & 25.81 \\
\hline KOM0 6 & 0.89 & & 99 & 4.65 & 22.70 \\
\hline KOM0 7 & 0.74 & & 109 & 7.15 & 23.14 \\
\hline KOM0 8 & 0.42 & & 108 & 4.23 & 24.34 \\
\hline KOM09 & 0.53 & & 58 & 4.37 & 24.83 \\
\hline KOM10 & 0.41 & 1.38 & 54 & 2.01 & 24.17 \\
\hline KOM11 & 0.41 & & 95 & 5.51 & 25.75 \\
\hline KOM12 & 0.50 & & 119 & 7.25 & 23.13 \\
\hline KOM13 & 0.56 & & 93 & 6.68 & 23.12 \\
\hline KOM14 & 0.48 & & 67 & 6.27 & 20.79 \\
\hline KOM15 & 0.71 & 2.44 & 78 & 6.93 & 24.08 \\
\hline KOM16 & 0.55 & 2.40 & 137 & 10.06 & 20.58 \\
\hline KOM1 7 & 0.45 & 1.39 & 65 & 2.19 & 23.59 \\
\hline KOM18 & 0.33 & 1.33 & 28 & 2.16 & 25.27 \\
\hline KOM19 & 0.52 & & 85 & 5.53 & 23.25 \\
\hline KOM20 & 0.39 & 1.64 & 67 & 3.79 & 24.53 \\
\hline KOM21 & 0.62 & & 108 & 8.60 & 21.84 \\
\hline KOM22 & 0.74 & & 117 & 8.30 & 22.05 \\
\hline KOM23 & 0.74 & & 105 & 6.40 & 24.31 \\
\hline KOM24 & 0.89 & & 68 & 5.16 & 19.68 \\
\hline KOM25 & 0.74 & 2.30 & 87 & 4.62 & 24.16 \\
\hline KOM2 6 & 0.60 & 2.86 & 142 & 11.15 & 21.96 \\
\hline KOM27 & 0.86 & 1.19 & 62 & 3.76 & 20.37 \\
\hline KOM28 & 0.76 & & 111 & 6.01 & 22.77 \\
\hline KOM29 & 0.61 & & 91 & 4.87 & 24.96 \\
\hline KOM30 & 0.60 & & 112 & 6.87 & 22.39 \\
\hline KOM31 & 0.74 & 2.48 & 133 & 6.19 & 26.13 \\
\hline KOM32 & 0.54 & & 107 & 4.55 & 23.17 \\
\hline KOM33 & 0.66 & & 116 & 6.27 & 24.38 \\
\hline KOM34 & 0.54 & & 114 & 4.60 & 24.59 \\
\hline KOM35 & 0.37 & 2.69 & 99 & 6.47 & 25.25 \\
\hline KOM36 & 0.52 & & 96 & 4.41 & 24.46 \\
\hline KOM37 & 1.16 & 0.96 & 40 & 6.01 & 23.10 \\
\hline KOM38 & 0.61 & & 102 & 6.57 & 23.85 \\
\hline KOM39 & 0.67 & & 117 & 6.12 & 22.94 \\
\hline KOM40 & 0.73 & 1.99 & 85 & 3.39 & 26.74 \\
\hline KOM41 & 0.64 & & 163 & 6.49 & 24.16 \\
\hline KOM42 & 0.64 & & 114 & 6.63 & 23.41 \\
\hline KOM43 & 0.81 & & 87 & 5.75 & 22.36 \\
\hline KOM44 & 1.31 & & 111 & 5.58 & 26.62 \\
\hline KOM45 & 0.74 & & 108 & 5.17 & 24.39 \\
\hline KOM4 6 & 0.97 & 1.50 & 85 & 6.31 & 21.68 \\
\hline KOM47 & 0.78 & & 110 & 8.28 & 23.30 \\
\hline KOM4 8 & 0.76 & & 93 & 6.10 & 22.07 \\
\hline KOM49 & 1.11 & 1.04 & 52 & 5.43 & 21.73 \\
\hline KOM50 & 1.04 & & 70 & 5.01 & 22.99 \\
\hline KOM51 & 0.84 & & 131 & 7.33 & 22.16 \\
\hline KOM52 & 0.83 & & 161 & 6.04 & 23.20 \\
\hline KOM53 & 0.55 & & 134 & 8.28 & 24.20 \\
\hline KOM54 & 0.80 & & 82 & 4.13 & 23.39 \\
\hline KOM55 & 1.27 & & 67 & 3.86 & 22.48 \\
\hline KOM5 6 & 1.31 & 1.48 & 69 & 3.22 & 22.43 \\
\hline KOM57 & 0.45 & 2.14 & 101 & 5.08 & 25.94 \\
\hline
\end{tabular}

Table 2. Concentrations of affected elements and $\mathrm{La} . \mathrm{Na}, \mathrm{Rb}, \mathrm{Cs}$ and $\mathrm{La}$ have been determined by NAA, while $\mathrm{K}_{2} \mathrm{O}$ by XRF. 


\begin{tabular}{|l|l|l|l|l|l|}
\hline Kommos & \multicolumn{1}{|c|}{ case 1 } & \multicolumn{1}{c|}{ case 2 } & \multicolumn{1}{c|}{ case 3 } & \multicolumn{1}{c|}{ case 4 } & \multicolumn{1}{c|}{ case 5 } \\
\hline Petrographic groups & 1 to 6 & 1 to 4 & 1 to 4 & 1 to 4 & 1 to 4 \\
\hline Elements not included & & & & Na, Rb, Cs & $\begin{array}{l}\text { Na, Rb, Cs } \\
\text { variances } \\
\text { estimated } \\
\text { from case 4 }\end{array}$ \\
\hline $\begin{array}{l}\text { Individuals not } \\
\text { included }\end{array}$ & & & $\begin{array}{l}\text { chemical } \\
\text { groups B, D, } \\
\text { E and } \\
\text { KOM40 }\end{array}$ & $\begin{array}{l}\text { chemical } \\
\text { groups B, D, } \\
\text { E and } \\
\text { KOM40 }\end{array}$ & $\begin{array}{l}\text { chemical } \\
\text { groups B, D, } \\
\text { E and } \\
\text { KOM40 }\end{array}$ \\
\hline total variation & $\mathbf{0 . 6 0}$ & $\mathbf{0 . 5 4}$ & $\mathbf{0 . 3 6}$ & $\mathbf{0 . 2 2}$ & $\mathbf{0 . 2 7}$ \\
\hline
\end{tabular}

Table 3. Total variation values of the original variation matrix (case 1) and the matrices that resulted after successive elimination of individuals and elements (cases 2 to 6$)$ 